Revised March 9, 2016

\title{
Infectious Complications in Obese Patients Following Trauma
}

\section{Short Title: Infectious Complications Post Trauma}

Bell $\mathrm{TM}^{1 *}$, Bayt $\mathrm{DR}^{1}$, Siedlecki $\mathrm{CB}^{2}$, Stokes $\mathrm{SM}^{1}$, Yoder ${ }^{1}$, Jenkins $\mathrm{P}^{1}$, and Fecher $\mathrm{AM}^{1}$

Author Affiliations:

1) Indiana University School of Medicine, Department of Surgery, Indianapolis, Indiana

2) Indiana University School of Medicine, Indianapolis, Indiana

Corresponding Author:

Teresa Bell

terebell@iupui.edu

317-274-7435

702 Rotary Circle, 022

Indianapolis, IN 46202

Author Contributions:

T. Bell, D. Bayt, S. Stokes, and J. Yoder devised and designed the study. T.Bell, D. Bayt, and S. Stokes analyzed and interpreted the data. T. Bell, D. Bayt, S. Stokes, J. Yoder, and C. Siedlecki drafted and revised the manuscript. P. Jenkins and A. Fecher critically revised the manuscript. 


\section{ABSTRACT}

Background: Obesity is a public health concern in the U.S. due to its increasing prevalence, especially in younger age groups. Trauma is the most common cause of death for people under 40 years of age. The purpose of this study is to determine the association between obesity and specific infectious complications following traumatic injury.

Materials and Methods: A retrospective analysis was conducted using data from the 2012 National Trauma Data Bank (NTDB). The NTDB defined obesity as having a BMI of 30 or greater. Descriptive statistics were calculated and stratified by obesity status. A hierarchical regression model was used to determine the odds of experiencing an infectious complication in patients with obesity while controlling for age, gender, diabetes, number of comorbidities, injury severity, injury mechanism, head injury, and surgical procedure.

Results: Patients with a BMI of 30 or greater compared to non-obese patients had increased odds of having an infectious complication ( $\mathrm{OR}=1.59,1.49-1.69)$. In addition to obesity, ISS greater than 29, age 40 years or older, diabetes, comorbid conditions, and having a surgical procedure were also predictive of an infectious complication.

Conclusions: Our results indicate that trauma patients with obesity are nearly $60 \%$ more likely to develop an infectious complication in the hospital. Infection prevention and control measures should be implemented soon after hospital arrival for patients with obesity, particularly those with operative trauma.

Keywords: Trauma, Obesity, Complications, surgical site infection, urinary tract infection, sepsis 


\section{INTRODUCTION}

In the United States, the obesity rate has continued to increase over the last twenty years resulting in a national epidemic [1,2]. From 2011 to 2012, 35\% of adults in the United States met criteria to be considered obese [3]. Obesity is defined as having a body mass index (BMI) between $30 \mathrm{~kg} / \mathrm{m}^{2}$ and $39.9 \mathrm{~kg} / \mathrm{m}^{2}$, and morbidly obese as having a BMI greater than or equal to $40 \mathrm{~kg} / \mathrm{m}^{2}$ [4]. Obesity is often considered a risk factor for patients with serious injuries because it is usually associated with other comorbid conditions including heart disease, malignant neoplasm, stroke, chronic lower respiratory disease, diabetes mellitus, influenza, and pneumonia $[5]$.

Currently, trauma is considered the most common cause of death of people younger than 40 years of age and the third most frequent cause of death overall in the United States [6].

Recent literature exploring the link between obesity and trauma has shown increased morbidity and complications in obese trauma patients $[1,4,7,8,9]$. However, despite abundant literature on obesity, the results of studies looking at trauma outcomes and how they may be impacted by obesity are inconsistent [10]. For instance, a study by Livingston et al. concluded that, when looking at length of stay and postoperative infection, BMI was not an independent predictor of these outcomes for trauma patients undergoing laparotomy [10]. Another study found that age, injury severity score (ISS), and comorbidity-polypharmacy score (CPS) impacted the outcomes of mortality, complications, and discharge location, but BMI did not [11].

While there are mixed results regarding the effects of obesity and complications following trauma, there is literature that suggests obesity is an independent risk factor for infection and pneumonia [2]. One such study found that morbidly obese trauma patients had increased odds of post-operative complications including pneumonia and urinary tract infection 
(UTI) compared to patients with a normal BMI [4]. These types of complications can increase the cost associated with trauma care and elevate the severity of infectious complications as over $70 \%$ of deaths from nosocomial infections are a result of surgical site infection (SSI) $[12,13]$.

Previous studies examining the association between obesity and health outcomes following trauma have used different definitions of obesity, age groups, and relatively small sample sizes from the local population. Furthermore, there was only one study that was found that examined the association between morbid obesity and trauma outcomes using national data [8]. This study aims to examine the association between obesity and specific infectious complications following traumatic injury using a large national dataset.

\section{MATERIALS AND METHODS}

A retrospective analysis was conducted using data from the National Trauma Data Bank (NTDB) for 2012. Patients between the ages of 18 and 89 years with an injury severity score (ISS) greater than 8 were included in the analysis. There were 91 hospitals missing $20 \%$ or more data pertaining to comorbidities, which were excluded from the study. In addition to the excluded hospitals, burns, other/unspecified injuries, missing injury types, drowning/submersion, poisoning, natural/environmental, bites and stings, suffocation, and overexertion injury mechanisms were excluded from analysis. People who had ED dispositions of home without services, died, transferred to another hospital, other, and left against medical advice were excluded from the analysis.

Obesity was defined by the NTDB as having a body mass index of greater than or equal to 30 $\mathrm{kg} / \mathrm{m}^{2}$. Chi-square tests were used to determine if there was a relationship between patient characteristics and obesity comorbidity. A hierarchical regression model was used to examine the probability of experiencing at least one of the following infectious complications: deep 
surgical site infection, organ/space surgical site infection, pneumonia, superficial surgical site infection, urinary tract infection (UTI), catheter-related blood stream infection (BSI), and severe sepsis. The association between obesity and having an infectious complication was evaluated using the SAS procedure GLIMMIX, which controlled for other patient-level factors associated with infectious complications and hospital random effects. The patient-level factors included in the model were obesity, diabetes, injury severity score (ISS), gender, injury type (blunt and penetrating), age groups, number of comorbid conditions other than obesity and diabetes, GCS motor score, and whether a surgical procedure was performed. Data analysis was performed using SAS version 9.4 (SAS Institute Inc., Cary, NC).

\section{RESULTS}

Of the 275,393 people included in the study, 14,210 (5.16\%) had obesity listed as a comorbidity. Of the 275,393 patients in the sample, 262,178 had data on complications. There were 13,704 (5.23\%) patients with complication data who also had obesity coded as a comorbidity. There were significant differences between patients with obesity and without obesity in regards to demographic and clinical characteristics including gender $(p<0.001)$, age $(p<0.001)$, injury type $(p<0.001)$, injury severity score $(p=0.006)$, GCS motor scores $(p=0.024)$, surgical procedure $(\mathrm{p}<0.001)$, and number of comorbidities other than obesity and diabetes $(\mathrm{p}<0.001)$ (Table 1).

Rates of specific infectious complications were compared between people with obesity and those without obesity. We found significant differences in rates of deep surgical site infection, organ/space surgical site infection, pneumonia, superficial surgical site infection, urinary tract infection (UTIs), catheter-related blood stream infection, severe sepsis, and infectious complication (which consists of having at least one of the previous listed complications) (all 
$\mathrm{p}<0.001$ ). Developing any hospital complication (including both infectious and non-infectious) was also more common in patients with obesity compared to those without obesity $(\mathrm{p}<.0001)$

\section{(Table 2).}

The results from the hierarchical regression model indicated that there was a significant association between obesity and experiencing an infectious complication (OR 1.59, 95\% CI:

1.49-1.69) (Table 3). Other patient level factors in the model that were significantly associated with developing infectious complications included injury severity, diabetes, number of comorbidities, GCS motor score, and surgical procedure. Obese comorbidity was found to be statistically significant for the association with pneumonia ( $\mathrm{OR}=1.64,95 \%$ CI: $1.58-1.77)$, organ/space surgical site infection (OR=2.27, 95\% CI: 1.80-2.89), superficial surgical site infection $(\mathrm{OR}=2.43,95 \% \mathrm{CI}: 1.95-3.03)$, catheter-related blood stream infection $(\mathrm{OR}=1.61,95 \%$ CI: $1.23-2.12)$, severe sepsis ( $\mathrm{OR}=2.33,95 \%$ CI: $1.98-2.74)$, urinary tract infection (UTI) $(\mathrm{OR}=1.46,95 \% \mathrm{CI}: 1.34-1.60)$, and deep surgical site infection (OR=2.8, 95\% CI: 1.95-3.42)

\section{(Table 4).}

\section{DISCUSSION}

The study found that there were higher percentages of infectious complications among people who have obesity reported as a comorbid condition. The percentage of deep surgical site infection, superficial surgical site infection, catheter-related blood stream infection, and severe sepsis was approximately twice as high in patients with obesity compared to patients without obesity. After controlling for potential confounders, including diabetes, we found that obesity increased the likelihood of developing an infectious complication by nearly $60 \%$.

This is consistent with findings from other studies that have examined the outcomes of trauma patients with comorbid obesity. Overall, obese patients have twice the relative risk of 
developing sepsis, UTI, or respiratory infections in the trauma/ICU setting [1]. In comparing normal BMI to a BMI of 30-39.9 with an ISS $\geq 16$ there is a 1.72 odds ratio for pneumonia and 1.82 for urinary tract infections [4]. In the ICU population $61 \%$ of obese patients had infections compared to $34 \%$ in the non-obese group [1]. Another study found that obesity was a predictor of nosocomial infections in trauma patients with an $\mathrm{OR}=4.69$ [14]. Our findings add to this literature by examining the association of obesity and individual infectious complications following traumatic injury using a large national sample from multiple institutions.

There are various reasons for the increased risk of infection associated with obese patients. Obesity is a chronic form of low grade inflammation that causes significant changes in the metabolic and immune systems. Primary adipose derived pro-inflammatory cytokines TNF $\alpha$, IL6 , and IL-1 $\beta$ are produced in excess in obese individuals and are thought to desensitize immune cells to inflammatory responses during actual infections [15]. In addition, adiponectin, an immunomudlatory adipokine, has decreased levels in obese patients which alter natural killer cell cytotoxicity and cytokine production by myeloid cells [15]. These conditions, which reduce the ability to fight infection, coupled with the trauma/ICU setting that is already associated with increased risk of infection due to patients' decreased mobility after injury, use of ventilation assisted breathing, and invasive line placement, likely account for the significant increase in infectious complications observed in obese patients following traumatic injury.

The clinical implications of these findings are that new protocols targeted to reduce infection in obese patients should be developed as this is a growing segment of the trauma population. Future studies should examine modifiable clinical risk factors and aim to produce better evidence-based guidelines for this at-risk population. For example, studies conducted in the bariatric surgery setting have found that inadequate dosing of antibiotic prophylaxis in obese 
patients can greatly increase the risk of developing a surgical site infection [16]. This suggests that development and adherence to specialized antibiotic guidelines with defined dosages and timing of administration for obese patients with operative trauma may reduce the likelihood of infection. Additionally, there are currently no process measures specific to obese patients for reducing the incidence of infection after trauma. Screening preoperative blood glucose levels and maintaining tight glucose control after surgery may be especially important in preventing infections in this population [17]. Additional staff may also be needed postoperatively to assist patients with mobilization, as early mobilization is known to lower the risk of wound infection after surgery [18]. Our results suggest that further investigation into infection prevention strategies targeting the obese trauma population is needed.

Our results are limited by the fact that they only represent patient level risk factors and do not include preventative risk factors such as antibiotic usage and doses, hand hygiene compliance, number of days with a Foley catheter, number of days with a central line, and personal protective equipment usage. In addition, the data only lists obesity as defined as having a BMI greater than or equal to 30. No specific information on height, weight, or BMI was available in the NTDB dataset and therefore validation of obesity status through other variables was not possible. It is possible that obesity coding practices differ across trauma centers and that some cases were not captured. We attempted to minimize the effect of poor coding practices by excluding hospitals with comorbidity data missing in $20 \%$ or more of cases.

\section{CONCLUSION}

The growing population of obese individuals in the United States almost certainly means that trauma centers will see an increase in obese patients being admitted to the ICU. While continued strategy formation for the improvement of management in the trauma ICU setting regarding 
invasive line use and ventilation are important to improve upon, special attention should be made for the obese population. Future studies should aim to design specific interventions for obese patients in the trauma setting. 


\section{REFERENCES}

[1] Bochicchio, G.V., Joshi, M., Bochicchio, K., Nehman, S., Tracy, J.K., Scalea, T.M. (2006). Impact of obesity in the critically ill trauma patient: a prospective study. J Am Coll Surg 203(4):533-538.

[2] Bloom, M.B., Ley, E.J., Liou, D.Z., Tran, T., Chung, R., Melo, N., Margulies, D.R. (2015). Impact of body mass index on injury in abdominal stab wounds: implications for management. Journal of Surgical Research. In press.

[3] Ogden, C.L., Carroll, M.D., Kit, B.K., Flegal, K.M. Prevalence of childhood and adult obesity in the United States, 2011-2012. JAMA 311(8): 806-814.

[4] Newell, M.A., Bard, M.R., Goettler, C.E., Toschlog, E.A., Schenarts, P.J., Sagraces, S.G., Holbert, D., Pories, W.J., Rotondo, M.F. (2007). Body mass index and outcomes in critically injured blunt trauma patients: Weighing the impact. J Am Coll Surg 204(5):1056-1061.

[5] Ryb, G.E., Dischinger, P.C. (2008) Injury severity and outcome of overweight and obese patients after vehicular trauma: A Crash Injury Research and Engineering Network (CIREN) study. J Trauma 64(2): 406-411.

[6] Diaz Jr., J.J., Norris, P.R., Collier, B.R., Berkes, M.B., Ozdas, A., May, A.K., Miller, R.S., Morris, J.A. (2009) Morbid obesity is not a risk factor for mortality in critically ill trauma patients. J Trauma 66(1): 226-31.

[7] Glance, L.G., Li, Y., Osler, T.M., Mukamel, D.B., Dick, A.W. (2014). Impact of obesity on mortality and complications in trauma patients. Ann Surg 259(3):576-581.

[8] Ditillo, M., Pandit, V., Rhee, P., Aziz, H., Hadeed, S., Bhattacharya, B., Friese, R.S., Davis, K., Joseph, B. (2014). Morbid obesity predisposes trauma patients to worse outcomes: A National Trauma Data Bank analysis. J Trauma Acute Care Surg 76(1):176-179.

[9] Brown, C.V.R., Neville, A.L., Rhee, P., Salim, A., Velmahos, G.C., Demetriades, D. (2005). The impact of obesity on the outcomes of 1,153 critically injured blunt trauma patients. $J$ Trauma 59(5):1048-1051.

[10] Livingston, D.H., Lavery, R.F., N'Kanza A., Anjaria, D., Sifri, Z.C., Mohr, A.M., Mosenthal, A.C. (2013). Obesity does not increase morbidity and mortality after laparotomy for trauma. The American Surgeon 79(3):247-252.

[11] Evans, D.C., Stawicki, S.P., Davido, H.T., Eiferman, D. (2011). Obesity in trauma patients: Correlations of body mass index with outcomes, injury patterns, and complications. The American Surgeon 77(8):1003-1008. 
[12] O’Keefe, G.E., Maier, R.V., Diehr, P., Grossman, D., Jurkovich, G.J., Conrad, D. (1997). The complications of trauma and their associated costs in a level I trauma center. Arch Surg 132:920-924.

[13] Harrop, J.S., Styliaras, J.C., Ooi, Y.C., Radcliff, K.E., Vaccaro, A.R., Wu, C. (2012). Contributing factors to surgical site infections. J Am Acad Orthop Surg 20(2): 94-101.

[14] Serrano, P.E., Khuder, S., Fath, J.J. (2010) Obesity as a Risk Factor for Nosocomial Infections in Trauma Patients. J Am Coll Surg 211(1):61-67.

[15] Milner JJ, Beck MA. (2012). The impact of obesity on the immune response to infection. Proceedings of the Nutrition Society 71(2):298-306.

[16] Freeman JT, Anderson DJ, Hartwig MG, Sexton DJ. (2011). Surgical site infections following bariatric surgery in community hospitals: a weight concern? Obes Surg 21(7):836-40.

[17] Fry DE. (2018) Surgical Site Infections and the Surgical Care Improvement Project (SCIP): Evolution of National Quality Measures. Surg Infect. 9(6):579-84

[18] Epstein NE. (2014). A review article on the benefits of early mobilization following spinal surgery and other medical/surgical procedures. Surg Neurol Int. 16;5(Suppl 3):S66-73 

Table 1. Descriptive Characteristics of Obese versus Non-Obese Patients

\begin{tabular}{|c|c|c|c|}
\hline & $\begin{array}{c}\text { Obesity } \\
\text { Comorbidity } \\
n=14,210\end{array}$ & $\begin{array}{c}\text { No Obesity } \\
\text { Comorbidity } \\
n=261,183\end{array}$ & $\mathrm{p}$ value \\
\hline Gender & & & $<0.001$ \\
\hline Male & $55.95 \%$ & $63.05 \%$ & \\
\hline Age Groups & & & $<0.001$ \\
\hline $18-40$ & $23.97 \%$ & $31.99 \%$ & \\
\hline $41-60$ & $35.65 \%$ & $27.47 \%$ & \\
\hline $61-89$ & $40.38 \%$ & $40.55 \%$ & \\
\hline Injury Type & & & $<0.001$ \\
\hline Blunt & $94.64 \%$ & $92.58 \%$ & \\
\hline Penetrating & $5.36 \%$ & $7.42 \%$ & \\
\hline Injury Severity Score & & & 0.006 \\
\hline 9 to 29 & $94.64 \%$ & $94.82 \%$ & \\
\hline 30 to 49 & $4.71 \%$ & $4.48 \%$ & \\
\hline 50 or higher & $0.91 \%$ & $0.71 \%$ & \\
\hline GCS Motor Scores & & & 0.0243 \\
\hline 1 to 2 & $7.97 \%$ & $7.64 \%$ & \\
\hline 3 to 4 & $1.69 \%$ & $1.99 \%$ & \\
\hline 5 to 6 & $90.33 \%$ & $90.37 \%$ & \\
\hline Surgical Procedure & $82.90 \%$ & $78.62 \%$ & $<0.001$ \\
\hline $\begin{array}{l}\text { Number of comorbidities } \\
\text { (excluding obesity and diabetes) }\end{array}$ & & & $<0.001$ \\
\hline 0 & $28.16 \%$ & $43.67 \%$ & \\
\hline 1 to 2 & $59.68 \%$ & $48.81 \%$ & \\
\hline 3 to 4 & $11.15 \%$ & $6.95 \%$ & \\
\hline 5 or more & $1.01 \%$ & $0.56 \%$ & \\
\hline Diabetes Comorbidity & $30.25 \%$ & $12.27 \%$ & $<0.001$ \\
\hline
\end{tabular}


Table 2. Complication Rates by Obesity Comorbidity

\begin{tabular}{lccc}
\hline Complication & $\begin{array}{c}\text { Obesity } \\
\text { Comorbidity } \\
\mathrm{n}=13,704\end{array}$ & $\begin{array}{c}\text { No Obesity Comorbidity } \\
\mathrm{n}=248,474\end{array}$ & $\begin{array}{l}\mathrm{p} \\
\text { value }\end{array}$ \\
\hline Deep Surgical Site Infection & $0.48 \%$ & $0.19 \%$ & $<0.001$ \\
Organ/Space Surgical Site Infection & $0.68 \%$ & $0.35 \%$ & $<0.001$ \\
Pneumonia & $7.35 \%$ & $4.34 \%$ & $<0.001$ \\
Superficial Surgical Site Infection & $0.81 \%$ & $0.31 \%$ & $<0.001$ \\
Urinary Tract Infection & $5.18 \%$ & $2.86 \%$ & $<0.001$ \\
Catheter-related Blood Stream Infection & $0.55 \%$ & $0.24 \%$ & $<0.001$ \\
Severe Sepsis & $1.54 \%$ & $0.55 \%$ & $<0.001$ \\
Infectious Complication & $12.98 \%$ & $7.33 \%$ & $<0.001$ \\
Any complication & $38.24 \%$ & $33.20 \%$ & $<0.001$ \\
\hline
\end{tabular}


Table 3. Predictors of Infectious Complications

\begin{tabular}{|c|c|c|c|}
\hline & $\mathrm{OR}$ & LCL & UCL \\
\hline \multicolumn{4}{|l|}{ Obesity } \\
\hline No Obesity Comorbidity & \multicolumn{3}{|c|}{ Reference } \\
\hline Obesity Comorbidity & 1.59 & 1.49 & 1.69 \\
\hline \multicolumn{4}{|l|}{ Gender } \\
\hline Male & \multicolumn{3}{|c|}{ Reference } \\
\hline Female & 0.98 & 0.95 & 1.02 \\
\hline \multicolumn{4}{|l|}{ Mechanism of Injury } \\
\hline Penetrating & \multicolumn{3}{|c|}{ Reference } \\
\hline Blunt & 1.06 & 1.00 & 1.13 \\
\hline \multicolumn{4}{|l|}{ Age Group } \\
\hline 18 to 40 & \multicolumn{3}{|c|}{ Reference } \\
\hline 41 to 60 & 1.24 & 1.18 & 1.29 \\
\hline 61 to 89 & 1.57 & 1.49 & 1.64 \\
\hline \multicolumn{4}{|l|}{ Diabetes } \\
\hline Not Diabetic & \multicolumn{3}{|c|}{ Reference } \\
\hline Diabetic & 1.20 & 1.14 & 1.26 \\
\hline \multicolumn{4}{|c|}{$\begin{array}{l}\text { Number of Comorbid Conditions } \\
\text { (excluding obesity and diabetes) }\end{array}$} \\
\hline 0 & \multicolumn{3}{|c|}{ Reference } \\
\hline 1 to 2 & 1.24 & 1.20 & 1.29 \\
\hline 3 to 4 & 1.91 & 1.79 & 2.03 \\
\hline 5 or more & 2.58 & 2.21 & 3.02 \\
\hline \multicolumn{4}{|l|}{ Injury Severity } \\
\hline 9 to 29 & \multicolumn{3}{|c|}{ Reference } \\
\hline ISS $50+$ vs. 9-29 & 3.23 & 2.88 & 3.62 \\
\hline ISS $30-49$ vs. $9-29$ & 3.21 & 3.04 & 3.38 \\
\hline \multicolumn{4}{|l|}{ GCS Motor Score } \\
\hline 1 to 2 & \multicolumn{3}{|c|}{ Reference } \\
\hline 3 to 4 & 1.11 & 1.02 & 1.21 \\
\hline 5 to 6 & 0.32 & 0.31 & 0.34 \\
\hline \multicolumn{4}{|l|}{ Surgical Procedure } \\
\hline No Surgical Procedure & \multicolumn{3}{|c|}{ Reference } \\
\hline Surgical Procedure & 3.90 & 3.65 & 4.17 \\
\hline
\end{tabular}


Table 4. Odds Ratios for Individual Infectious Complications for Obesity Comorbidity compared to No Obesity Comorbidity

\begin{tabular}{lll}
\hline & OR & $95 \%$ CI \\
\hline Pneumonia & 1.64 & $1.58-1.77$ \\
Organ/space Surgical Site Infection & 2.27 & $1.80-2.89$ \\
Superficial Surgical Site Infection & 2.43 & $1.95-3.03$ \\
Catheter-related Blood Stream Infection & 1.61 & $1.23-2.12$ \\
Severe Sepsis & 2.33 & $1.98-2.74$ \\
UTI & 1.46 & $1.34-1.60$ \\
Deep Surgical Site Infection & 2.80 & $1.95-3.42$ \\
\hline
\end{tabular}

The models used to calculate these odds ratios controlled for ISS, gender, injury type, age group, diabetes comorbidity, and GCS motor score. 